\title{
Racionalización y poder La cuestión de la legitimidad en Weber como referente de la acción política
}

\author{
Nicolás Fleet*
}

\begin{abstract}
Resumen
Este artículo desarrolla, en tres pasos, una perspectiva original de la teoría de la dominación de Max Weber. El primer paso establece un vínculo necesario entre las formas típicas de dominación política y los intereses sociales, de modo que toda acción política debe legitimarse ante el interés general. El segundo paso explica las crisis de legitimación como una respuesta a cambios de identidad en la base social de la dominación política, de tal forma que se introduce un concepto dinámico de legitimidad. El tercer paso establece que los valores que habitan en las formas legitimas de dominación política son usados como orientaciones simbólicas por parte de intereses sociales y acciones políticas particulares, de manera que toda forma de legitimación de la autoridad encierra, en sus propias premisas, los argumentos que justifican luchas políticas hacia la modificación de los esquemas de dominación.
\end{abstract}

Palabras clave: legitimidad, dominación, acción política, democratización.

\begin{abstract}
This article develops, in three steps, an orignal perspective of Weber's legitimacy theory. The first one, establishes a necessary link that exists between the typical forms of legitimate domination and the social interests, in such a way that every political action that purse the realization of its interests has to legitimate itself before the general will. The second explains the legitimation crises as a response to indentity changes at the social base of the political domination and, in so doing, it introduces a dinamic concept of legitimacy. The third step states that the values that dwell in legitimate forms of political domination are used as symbolic orientations by particular social intersts and political actions, in a way that each form of authority legitimation encapsulate, in its own premises, the arguments that justify political struggles aiming toward the modification of the domination schemes.
\end{abstract}

Key words: legitimacy, domination, political action, democratization.

\footnotetext{
Nicolás Fleet, chileno, Licenciado en Sociología Universidad de Chile, MSc en Sociología Política de la London School of Economics and Political Science. Integrante de la Secretaría Ejecutiva de la Comisión Nacional de Acreditación, nicholas.fleet@gmail.com, 2690224.
} 
Racionalización y poder. La cuestión de la legitimidad en Weber como referente de la acción política - Nicolás Fleet

\section{Orientaciones generales}

El punto de arranque de la sociología weberiana siempre va a ser el individuo. En efecto, la acción social es entendida por Weber a partir del sentido subjetivo mentado y no por referencia a determinadas orientaciones normativas vigentes en la sociedad y que son incorporadas en la conciencia de los sujetos. La descripción de los procesos sociales también se acoge a la misma perspectiva, poniendo el interés particular, tanto material como ideal, como el motor de las dinámicas sociales y de sus procesos de institucionalización. Weber, se suele afirmar, adscribe al individualismo metodológico y, en ese sentido, se resiste a interpretar a la sociedad recurriendo a modelos heurísticos tomados de la "filosofía de la historia" o de las teorías decimonónicas de la evolución, de modo que siempre el centro de su análisis radica en las constelaciones de sentido que están a la base de las estructuras sociales históricas. En suma, Weber rechaza el tipo de análisis sociológico que le otorga a los procesos sociales un estatus o sentido superior al interés particular. De acuerdo a esta perspectiva, según Parsons, Weber da cuenta de un individualismo muy enraizado más en motivos éticos que en estrictamente científicos, el cual apela a la autonomía y responsabilidad del individuo, especialmente contra la autoridad heredada de la tradición (Parsons, 1949).

En general, los autores de la tradición utilitarista estuvieron preocupados de justificar la libertad individual frente al influjo de la autoridad. Por cierto que esta preocupación es evidente en el pensamiento weberiano, cuya teoría de la dominación siempre va a estar, por un lado, organizada en torno a intereses particulares específicos sobre la que esta dominación se erige y, por el otro, atendiendo a una necesaria diferenciación entre los sistema sociales que ponga coto a la excesiva centralización del poder. Esto con especial énfasis en la caracterización que Weber hace del tipo de dominación legal racional, donde justamente convergen, en el marco de la sociedad occidental capitalista industrial, la razón formal, en tanto incremento en las capacidades técnicas para 
perseguir, de modo continuo, fines determinados, con la dominación, en tanto administración burocrática de la vida cotidiana que tiende a extender crecientemente su alcance conforme se incrementan las exigencias de estabilidad o calculabilidad sobre la sociedad. En otras palabras, Weber está buscando en las formas concretas que asume el proceso de racionalización en occidente sus "manifestaciones progresivas y regresivas" (Marcuse, 1970: 117), a partir del criterio normativo que la defensa teórica de la libertad individual le ofrece para emitir juicios de valor acerca de las consecuencias de este proceso.

"[...] cuando Weber habla de la racionalización, considera que esta capacidad técnica de las instituciones sociales permite a los individuos superar su dependencia de las formas de dominación tradicionales; pero al mismo tiempo, esa misma capacidad técnica representa un peligro inédito en su magnitud para la libertad de los individuos, esto es, aparece la amenaza de esa 'jaula de hierro', de la que existen pocas posibilidades de escapar" (Serrano, 1994: 64).

La pregunta por la legitimidad de la dominación, en este sentido, va a ser tomada por Weber aludiendo a la perspectiva sociológica y el criterio normativo planteados arriba. La legitimidad constituye la justificación de la imposición de mandatos particulares sobre los miembros de una sociedad. Se trata de la pregunta por la naturaleza de la cuestión política, esto es, sobre cómo determinados contenidos particulares adquieren validez universal para el conjunto. La referencia política al orden, a la validez del orden, es abordada poniendo la vista en las relaciones de dominación y de conflicto están en su fundamento. Es en este punto que el pensamiento sociológico de Weber es capaz de sintetizar ejemplarmente las dos entradas predominantes en el estudio del hecho político: aquella que pone el énfasis en la preocupación política por el buen orden, y aquella que, al contrario, entiende a la política como el resultado de los conflictos que se verifican en 
Racionalización y poder. La cuestión de la legitimidad en Weber como referente de la acción política - Nicolás Fleet

las sociedades concretas. En otras palabras, para Weber el orden social se explica a partir de las relaciones de dominación de unos individuos sobre otros, y la legitimidad permite entender como es posible que, a pesar del conflicto y de la dominación, es decir, de la imposición de intereses particulares, permanezca el orden social como válido para sus miembros, quienes al someterse a él le otorgan legitimidad a las desigualdades y asimetrías que constituye tal orden y a los mandatos que de él se desprenden. De este modo las sociedades contienen sus conflictos en la medida que los subgrupos que lo forman conceden legitimidad a la estructura de autoridad del grupo.

La insistencia de Weber acerca de que el orden social es válido para sus miembros solo en la medida en que el contenido de los mandatos evacuados de la autoridad que está a la cabeza de tal orden son tenidos como legítimos para quienes obedecen, implica una crítica radical a aquellas perspectivas teóricas que justifican la legitimidad de determinadas formas de dominación política institucionalizada ya sea por la 'naturaleza de las cosas', 'el devenir de la razón', o incluso la 'justicia'. Esta manera que Weber tiene de plantear la pregunta por la legitimidad presupone una crítica a su noción tradicional, en la que se considera que el orden social legítimo es aquel que se adecua a un orden trascendente. La crítica weberiana consiste en resaltar que los juicios sobre la legitimidad implican una referencia a valores y que éstos, por su parte, no pueden ser deducidos de los hechos. Tal diferenciación conduce a la tesis neokantiana de que mientras solo los enunciados empíricos son susceptibles de ser verdaderos, los enunciados normativos remiten a una creencia o consenso social.

Para Weber, no hay ningún medio a través del cual el racionalismo científico pueda suministrar validez a un ideal ético en comparación con otro. Asimismo "no puede haber ningún sentido en el que la historia pueda ser racional, como postulaban el 'idealismo objetivo' hegeliano o el marxismo, para los cuales el desarrollo social del ser humano evoluciona progresivamen- 
te hacia la consecución de ideales racionalmente determinados" (Giddens, 1976: 66). La verdad y la bondad no mantienen ninguna relación histórica definida entre sí.

La legitimidad de determinado orden social no es entonces consecuencia de la imposición lógica de verdades alcanzadas o reveladas que tienen una vinculación inmanente con el avance de la razón en las sociedades modernas. Al contrario, la diferenciación de las sociedades deriva en un conflicto inagotable entre sistemas éticos divergentes que no puede ser resuelto nunca por el desarrollo del conocimiento racional. Lo que si admite Weber es que la legitimidad de un orden social que distribuye asimétricamente los recursos de coacción, las oportunidades materiales de vida y la influencia, solo puede ser encontrada en las creencias compartidas de la sociedad.. Independientemente del contenido de tales valores, lo que a Weber interesa pesquisar es el anclaje de éstos en los estratos sociales, es decir en determinados intereses materiales orientados a participar de la distribución del poder en la sociedad y decidir sobre su conducción. De esta forma, las instituciones sociales pasan a mecanismos de integración entre intereses que son particulares y valores generales o creencias compartidas que sostienen la creencia de que tales instituciones existentes son las más apropiadas para la sociedad. La legitimidad, entonces, se muestra como una mediación social entre tales intereses particulares y los valores que soportan la solidaridad de la sociedad en su conjunto. "Es la representación de la validez del orden la que conecta la acción con aquel" (Mayol, 2002: 40). En otras palabras, no hay posibilidad de ejercer un dominio sistemático sobre la sociedad sin revestir a la autoridad y sus mandatos con el prestigio de la legitimidad, a su vez que no hay asidero de tales pretensiones de legitimidad sin apelar a los valores y creencias compartidas que aseguran la solidaridad e integración social. A este respecto y considerando al hecho político como articulado en torno a estas dos exigencias "se puede sugerir que para él (Weber) las condiciones de solidaridad basadas en ideas e intereses y el orden moral de la autoridad basada en la creencia 
Racionalización y poder. La cuestión de la legitimidad en Weber como referente de la acción política - Nicolás Fleet

en la legitimidad son dos perspectivas a través de las cuales una mirada comprensiva de la sociedad puede ser obtenida" (Bendix, 1962: 288).

En general, una situación de dependencia colectiva es suelo fértil para el desarrollo de la autoridad. "La influencia de un individuo sobre otro no puede convertirse en autoridad legítima, porque solo las normas compartidas por una colectividad pueden legitimar el control social y solo el refuerzo colectivo de la sumisión hacen la obediencia independiente de la influencia personal del superior sobre el individuo subordinado"(Blau, 1970: 158). La ilusión de que un individuo o grupo puede imponer su decisión con independencia de la mediación normativa del orden institucional es una consecuencia de sobrevaluar la perspectiva de la teoría de la acción en detrimento de la teoría de la estructura social.

La legitimidad, o la pretensión de legitimidad, al final, no es otra cosa que la justificación de las asimetrías de poder que se verifican en el ámbito del funcionamiento del sistema social, y de las operaciones y decisiones que de él provienen, en el ámbito normativo de la sociedad. Esto asegurado institucionalmente. La legitimidad consiste, por lo tanto, en el anclaje institucional entre la racionalización social que tiende a la diferenciación y jerarquización de posiciones en la sociedad e integración social, como el conjunto de valores que determinan la cohesión e identidad del grupo, de modo que constituye el imperativo de someter los procesos instrumentales a la mediación planteada por criterios normativos formulados universalmente, es decir, válidos. En total, la legitimidad remite a la tarea política de presentar los intereses particulares contenidos en los mandatos de la autoridad como si fueran universalmente válidos para el conjunto de la sociedad, de tal suerte que el contenido de tales mandatos se convierten en máxima para quienes obedecen y los imperativos de la autoridad se traducen en sometimiento voluntario. 
Ahora bien, Weber ve que las orientaciones normativas compartidas de la sociedad moderna, que justifican la dominación de la autoridad legal-racional y de la burocracia como cuadro administrativo, reaccionan a la pluralidad de valores e intereses particulares vigentes y sus exigencias de estabilidad y orden a partir de difusión y predominio de la racionalidad formal. Esto significa que en la esfera de la política, del derecho o de la economía capitalista se instala el énfasis hacia la optimización de los procedimientos para alcanzar fines que están determinados externamente. Cuando la solución al politeísmo de valores propio de las sociedades modernas se resuelve por medio del plano común que puede ofrecer la técnica, el saber experto y los consensos operacionales, la pretensión de legitimidad anclada en valores válidos para la colectividad queda vaciada de contenidos materiales. Por una parte los valores materiales sostenidos por la sociedad y que remiten a finalidades colectivas o a la búsqueda del bien común, son excluidos de la empresa política y económica, que solo sirve a intereses instrumentales particulares. Por la otra, los impulsos motivacionales de que se nutre el modo racional de vida pueden terminar siendo ahogados por una cosificación creciente de las relaciones sociales en términos de dinero y poder. En ambos casos los resultados del proceso de racionalización social que se expresan en la nueva libertad abierta por el desarrollo progresivo de las capacidades instrumentales de la empresa capitalista y el Estado burocrático para la consecución fines diversos, en la objetividad de la administración que sirvió de antídoto a la arbitrariedad propia de los poderes tradicionales, la igualdad que consolidó la ley en tanto sometimiento del gobierno al control de los representantes del pueblo y la abolición de los privilegios plutocráticos, tienen, en la perspectiva de Weber, efectos equívocos. La libertad individual está en peligro de quedar sometida a los imperativos de la administración formal, y los valores compartidos de la sociedad reducidos a un asunto de cálculo.

"La tesis de Weber consiste en mantener que la racionalidad formal tiende a imponerse a largo plazo sobre 
Racionalización y poder. La cuestión de la legitimidad en Weber como referente de la acción política - Nicolás Fleet

cualquier principio proveniente de la racionalidad material. El reto que tienen que afrontar los hombres para conservar su libertad es, según Weber, el de mantener un grado de racionalidad material frente a la expansión parasitaria de la racionalidad formal sobre todos los ámbitos de la vida humana" (Serrano, 1994: 72).

No es correcto, entonces, atribuir a Weber una interpretación de los procesos de racionalización como un tránsito implacable hacia el imperio de la racionalidad formal y técnica sobre el ámbito normativo de la sociedad. No se trata de que los procedimientos formales de la ley se terminen imponiendo sobre el sentido de la justicia, o que la actividad continua de la burocracia racional solo se oriente a extender el dominio calculable sobre la sociedad civil, ni que la economía nacional, racionalmente ejecutada, tenga por finalidad solo intereses instrumentales dejando la preocupación por la satisfacción de las necesidades de la población y el abastecimiento como resultados o consecuencias no esperadas de la acumulación privada. Al contrario, para Weber, el conflicto entre la racionalidad formal y sustancial no tiene una solución última. Ningún grado de formalización puede erradicar por completo la creencia en que la legitimidad del orden legal va más allá de la ley actual y sus valores instrumentales. Es terreno propio del conflicto político el incorporar orientaciones normativas materiales en el frío universo de la igualdad formal. "[...] la imagen de una lucha por el poder que se desarrolla en un marco jurídico y por lo tanto muy concreto, determina las proposiciones prácticas de Weber para la solución de los problemas sociales" (Mommsen, 1971: 110). Weber, en consecuencia, está preocupado de las formas concretas que asume el conflicto político en las sociedades históricas, siempre elevando su defensa de la libertad individual tanto frente a la amenaza de una opresiva expansión del dominio burocrático, como frente a los conflictos particulares que, en nombre de demandas por justicia social y leyes especiales para los desposeídos, termine por abolir las garantías de igualdad aseguradas por el modo racional de dominación. Finalmente su 
pensamiento político y sociológico estriba en encontrar la fórmula de representación de intereses que combine satisfactoriamente los imperativos del control burocrático con el sentido y la institucionalización de demandas ancladas en llamados a la justicia sustancial por parte de un liderazgo democrático y sometido al examen de las masas.

Es posible sostener, a este respecto, que el énfasis teórico sobre los tipos ideales de dominación y sus pretensiones de generalización contribuyen a oscurecer las tensiones, conflictos y contradicciones que Weber connota y valora en la caracterización del avance de la dominación política como actividad racional en las sociedades modernas. Me abstengo, de este modo, de hacer un análisis exhaustivo de tales tipos ideales, centrando, más bien, la perspectiva en los intereses ideales y materiales involucrados y que determinan la conducta política de los actores sociales que impulsan el proceso de racionalización.

\section{Las bases sociales de la dominación legítima}

El núcleo del pensamiento sociológico de Weber está constituido por la referencia al poder como el motor de los procesos históricos y su objetivación en determinadas formas concretas de estructura social. Consecuentemente, el poder aparece en la sociología de Weber como una capacidad instrumental natural o presocial de los individuos, que les permite realizar sus intereses particulares. Esta concepción está en directa vinculación con la especial atención que Weber le otorga al modelo teleológico de acción racional, donde el poder del individuo se encuentra en su capacidad de controlar los medios disponibles para la obtención de fines dados. De la misma forma que para Weber los procesos constitutivos de la sociedad europea occidental son aterrizados a la teoría de la acción mediante el privilegio que recibe el tipo puro de acción racional con arreglo a fines, el poder aparece como una categoría central para dar cuenta de la lógica de la racionalización social que, al institucionalizar tal tipo de acción instrumen- 
Racionalización y poder. La cuestión de la legitimidad en Weber como referente de la acción política - Nicolás Fleet

tal en las esferas organizativas del Estado y del mercado, incrementa las capacidades de acción en la consecución de fines pero también implica el riesgo de que tal poder institucionalizado se vuelva autárquico y no responda a los intereses de la totalidad. En resumen, Weber quiere dar cuenta de las condiciones de existencia de las sociedades modernas aludiendo a una combinación estable y creciente entre racionalidad y poder de tal modo que, cada vez más, aquello que ha sido tenido como condiciones de la acción, su entorno, se convierte, por medio del saber científico, en medios controlables y sometidos a la voluntad particular, lo cual, desde luego, no implica mayor libertad para la sociedad vista globalmente.

En fin, para Weber "poder significa la probabilidad de imponer la propia voluntad dentro de una relación social contra toda resistencia y cualquiera que sea el fundamento de esa posibilidad" (Weber, 1997: 43). Sin embargo, tal imposición de voluntad no implica la negación de la voluntad de quien se somete, sino que toda relación de poder debe contar, al menos, con la participación de una voluntad de imponer y una voluntad de obedecer. Es clara aquí la referencia al pensamiento de Nietzsche y al decisionismo, donde el poder es la fuerza que está a la base de la resolución de los conflictos y la instalación del orden. Frente a la pluralidad de intereses y valores que se constata con el creciente avance de la diferenciación social, el poder, de algún modo, es tenido tanto como la fuente de la unidad y permanencia de la sociedad así como también el vehículo de su innovación. La vida social entera se teje en torno a las relaciones de poder, donde coinciden la libertad de ejercer voluntad de poder, con la libertad de obedecer, siendo terreno de las decisiones individuales la vinculación con determinados ideales normativos que justifican y otorgan contenido al poder. Weber estaba convencido de que los ideales normativos se imponen como obligatorios para los sujetos por efecto de decisiones personales.

Distintos son los motivos y los intereses que están a la base 
de las decisiones de los miembros de determinado orden social para someterse voluntariamente a los mandatos emanados de la autoridad. "Es evidente que, en la realidad, la obediencia de los súbditos está condicionada por muy poderosos motivos de temor y de esperanza (temor a la venganza del poderoso o de los poderes mágicos, esperanza de una recompensa terrena o ultraterrena)" (Weber, 1981: 86). Según lo anterior, el sometimiento al poder de la autoridad puede afirmarse, para comenzar, en la pura coacción, lo cual, de todas formas, se expresa en el plano de la decisión individual como el temor a subvertir el orden y cuestionar la leyenda del grupo dominante. Más evidente es la conexión entre el interés particular con el sometimiento a las prerrogativas del orden cuando existe una retribución específica que está en juego. Tal puede apoyarse en una imagen de mundo que tenga la capacidad de darle sentido al sufrimiento y la opresión actuales en virtud de la promesa de una retribución en un plano trascendental. $\mathrm{O}$, como caso típico, cuando el sometimiento y la lealtad de los individuos con la autoridad del grupo están condicionados a la obtención presente de beneficios específicos, retribuciones materiales que comúnmente reciben el nombre de clientelismo. Sea cual sea el caso, Weber señala que tales motivaciones arrancan de un interés individual que se ajusta a las exigencias de obediencia a los mandatos de la autoridad y al cumplimiento de pautas de acción prescritas por el orden social no porque necesariamente comparta o esté de acuerdo con el contenido de tales mandatos y los imperativos de tal orden, sino porque encuentra beneficios individuales que se desprenden de su observancia. De este modo, en el tipo de acción racional con arreglo a fines, orientado a la autoconservación de los sujetos, hay una fuente permanente de obediencia que se justifica por encontrar en las consecuencias externas del orden social, y no en su contenido, determinadas expectativas de satisfacción de intereses particulares, sean éstos ideales o materiales. A esto se le agrega también como contraste el hecho que la obediencia puede ser explicada por una acción que en su sentido muestra conformidad con la costumbre 
Racionalización y poder. La cuestión de la legitimidad en Weber como referente de la acción política - Nicolás Fleet

y estado de las cosas como ha sido siempre, de tal manera que responde a una conducta arraigada, automática e irreflexiva, que tampoco otorga validez al orden social y legitimidad a su autoridad de acuerdo al contenido que a éstos justifican.

Ahora bien, la estabilidad y permanencia de una relación de poder (lo que Weber llama dominación) requiere ya de la mediación efectiva del orden social, es decir que éste sea tenido por válido y la autoridad que lo conduce como legítima, considerando en la acción de los sujetos que está orientada a la obediencia la incorporación de los contenidos que justifican y legitiman la dominación. La precisión que acá se puede hacer radica en encontrar "causas" que orientan la continuidad de la acción en torno a la validez del orden social, mientras que solo en las creencias de los sujetos es posible dar cuenta de la legitimación, en un plano normativo, de la autoridad que está a la cabeza de este orden válido. De algún modo, la perspectiva de la legitimidad consiste en una reformulación sociológica, orientada a captar el sentido de la acción, de las consideraciones acerca de la validez del orden como causas que determinan regularidades en el comportamiento (Turner et al, 1994: 100-101).

Lo anterior implica que el poder no puede reducirse a la simple fuerza, ni al esquema de comportamiento de individuos aislados. Para Weber la legitimidad requiere fundamentarse a nivel de una "racionalidad de conjunto".

"La dominación [...] puede fundarse en distintos motivos: dependen directamente de una constelación de intereses, o sea de consideraciones utilitarias por parte del que obedece; o [...] también de la mera 'costumbre', de la ciega habituación a un comportamiento inveterado, o [...] en el puro afecto, en la mera inclinación del súbdito. Sin embargo, la dominación que se fundará en tales motivaciones será inestable".

Weber afirma entonces que la estabilidad del orden social, 
es decir que la acción no se oriente a transgredir sus límites, así como la permanencia de la dominación remiten a un 'sentido' que no se restringe al puro interés individual concreto ni a la costumbre, incluso tampoco que se limite a una adhesión afectiva a la autoridad, sino que guía a la acción social de acuerdo a valores, vigentes para el conjunto de la sociedad sobre la cual la autoridad tiene predominio, que sirven para justificar y legitimar la dominación. En otras palabras, y tal como ya ha sido planteado, la legitimidad de la autoridad y la validez del orden dependen fundamentalmente de que los valores que constituyen la solidaridad del conjunto de la sociedad sirvan como argumento de la dominación y orienten, en este sentido, la acción voluntaria y consciente a la obediencia. La dominación debe arraigarse en el plano normativo de la sociedad, no solo en el plano instrumental, plano normativo que asegura la solidaridad del conjunto y define su propia identidad, es decir, quiénes son los portadores concretos de tales valores.

Al ensayar una entrada comprensiva sobre el problema de la dominación política desde la perspectiva weberiana resulta ineludible entender cómo tanto la justificación como la transformación de los modos de dominación es visible a partir de los valores que la sustentan. Estos valores, a su vez, no deben ser entendidos por sí mismos sino que siempre remitiéndolos a sujetos sociales concretos que los vinculan a sus intereses particulares y los transforman en orientaciones para la acción social, bien orientada a la conservación del orden y de la dominación o bien a su impugnación.

Para ahondar en esta perspectiva, los estudios de Weber sobre sociología de la religión nos permiten acceder, por una parte, a las imágenes de mundo como ideas que justifican la dominación tradicional y, por la otra, al anclaje que tales ideas y valores tienen en estratos sociales específicos como una manera de comprender en qué medida las imágenes de mundo son expresivas de la identidad de sociedades concretas. En definitiva la preocu- 
Racionalización y poder. La cuestión de la legitimidad en Weber como referente de la acción política - Nicolás Fleet

pación de Weber consiste en dar cuenta cómo las ideas que dan forma a las imágenes religiosas del mundo y que están a la base de los órdenes tradicionales responden al interés particular de determinados estratos sociales relevantes.

Según Weber, en un primer momento, el primitivo culto de la comunidad y, sobre todo, el de las comunidades políticas, excluía todos los intereses individuales. El dios tribal, el dios local, el dios de la cuidad y del imperio, se cuidaba únicamente de intereses que incumbían a la totalidad: la lluvia, el sol, la caza, la victoria sobre los enemigos. En este sentido la religión, en comunidades no diferenciadas, constituyó una fuerza vinculante y de identificación del grupo. Si se quiere poner en términos durkhemianos, la conciencia colectiva predominaba sobre los intereses particulares. En un contexto de este tipo la religión ofrecía una fuente privilegiada de legitimación del orden social, donde no solo las representaciones colectivas daban forma a una divinidad donde la totalidad social tenía cabida, sino que también los ritos definían prácticas que conservaban el orden en el tiempo, de acuerdo a las directrices planteadas por los mitos fundantes.

No obstante, la evolución de las comunidades tradicionales hacia formas más complejas implicó un tipo de diferenciación que no siguió pautas horizontales de segmentación únicamente, sino que también tuvo lugar una jerarquización en estratos sociales, donde son el poder y la dominación los determinantes básicos de un esquema de relaciones sociales caracterizado por individuos e intereses particulares que se imponen sobre el resto. Aquello requiere de justificación, y Weber en este punto usa el concepto de "teodicea" como el primer impulso hacia la racionalización de las imágenes de mundo en comunidades diferenciadas por relaciones de poder, en las cuales existe una fuerte demanda por explicar el "sentido" del reparto de los bienes entre los hombres.

"Al tratar el sufrimiento como síntoma del odio divino y de la culpa secreta, la religión satisfacía psicológicamente una necesidad muy general. El afortunado se contenta 
rara vez con el hecho de la posesión de su fortuna. Siente, además, la necesidad de tener derecho a ella. Quiere convencerse de que la ha 'merecido', sobretodo en comparación con los demás. Y quiere también, por consiguiente, poder creer que a los menos dichosos también les acontece únicamente lo que se merecen cuando no poseen la misma dicha que él. La felicidad quiere ser 'legítima'. Si con esta expresión general, 'felicidad', significamos todos los bienes del honor, el poder, la posesión y el goce, estamos ante la fórmula más universal de aquel servicio de legitimación que la religión tenía que prestar al interés interno y externo de todos los poderosos, poseedores, vencedores, sanos, o brevemente, felices: la teodicea de la felicidad" (Weber, 2001: 237-238).

Ahora bien, en la medida en que tales comunidades tradicionales siguieron curso a sus procesos de diferenciación estratificada, con las formas de autoridad conexas a estas tendencias, el problema de la teodicea se volvió un asunto mucho más complejo de resolver y grados más elevados de racionalización ética fueron necesarios para la justificación de la dominación. En concreto, la desgracia individual inmerecida, el sufrimiento, constituyeron hechos demasiado frecuentes. "No solamente desde el punto de vista de una 'moral de esclavos', sino según las propias pautas del estrato dominante, era demasiada la frecuencia con que no les iba mejor a los mejores, sino a los peores'" (Weber, 2001: 241). Era necesaria entonces cierta inversión en los valores, y complementar la fundamentación de la dominación en el mérito de quienes detentan el poder y la autoridad con una "teodicea del sufrimiento", lo cual plantea una tensión manifiesta entre las pautas de la clase dominante y la moralidad de los esclavos, para quienes los "malos" tenían éxito, no los "buenos". En este sentido, la palanca que determina la legitimación de la dominación en estas comunidades tradicionales jerarquizadas arranca de una imagen de mundo que pone la "compensación" como promesa: esperanza de mejor vida en este mundo (reino mesiánico) o en el más allá 
Racionalización y poder. La cuestión de la legitimidad en Weber como referente de la acción política - Nicolás Fleet

(paraíso). Se asocia a este proceso de racionalización el desarrollo de una ética religiosa racional que ha tenido una raigambre positiva y originaria en la estructura interna de los estratos con menor valor social. Para Weber, las religiones de salvación que sirven de legitimación de la autoridad tradicional encuentran su lugar habitual en las clases menos privilegiadas.

Finalmente, la idea que está presente en toda esta argumentación, es que, por una parte, las instituciones tradicionales, en tanto prácticas estables que expresan relaciones de dominación, tienen sentido si las comprendemos como la combinación entre ideas agrupadas en imágenes religiosas de mundo que, aún cuando tengan vigencia para el conjunto de estas comunidades tradicionales, expresan intereses particulares:

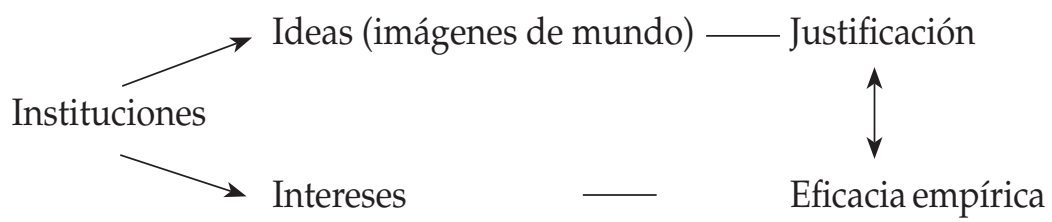

Por otra parte, queda claro ya que evolución o racionalización de estás imágenes de mundo, cuales dar forma en último término a la identidad del grupo social, "no solo debe pensarse como un proceso teórico, sino también como una consecuencia de la historia de los conflictos sociales" (Serrano, 1994: 89). A la vez, "el desarrollo de la racionalización depende de fuerzas que no son ellas mismas racionales" (Giddens, 1976: 67). Se trata de la lucha por alcanzar el reconocimiento simbólico dentro de la comunidad por parte de los estratos dominados y, aunque dicho reconocimiento tenga como campo privilegiado de las disputas el ámbito normativo planteado por las imágenes de mundo, estás van a jugar un papel activo en las transformaciones sociales, en la medida en que se encuentran ligadas a los interés particulares.

Como una primera entrada, vamos a entender que la domi- 
nación carismática se conecta con este conflicto fundamental del tipo de dominación tradicional. En efecto, Weber sostiene: "En las épocas prerracionalistas tradición y carisma se dividen entre sí la totalidad de las direcciones de orientación de la conducta" (Weber, 1997: 197). Digamos en este punto que aquellos intereses materiales e ideales de los estratos dominados, pospuestos en una promesa futura o trascendental, reciben atención de parte de la dominación carismática, la cual encuentra su legitimidad fundamentalmente de acuerdo a consideraciones éticas materiales, es decir, se basa en la creencia de los adeptos de que el líder carismático es el portador de determinados "bienes de salvación". La noción mesiánica del carisma justamente implica un cuestionamiento a la cotidianidad del orden tradicional basándose en la apelación a valores sustanciales que están asociados a una imagen social y extrajurídica de la justicia de acuerdo a la verdad revelada. En virtud de lo planteado, la dominación carismática presenta un impulso revolucionario característico, que la figuran, en su vinculación explícita con las convicciones religiosas, entre los motores más poderosos de la transformación social.

En la medida en que se insiste en el carácter material de la dominación carismática me refiero, por ejemplo en el ámbito de la dominación de la justicia, a su énfasis a rechazar los procedimientos formales y buscar la equidad en la decisión: "La justicia auténticamente carismática hace siempre lo siguiente: es en su forma pura la extrema contraposición a la vinculación formal y tradicional, y es tan independiente de la santidad de la tradición como de las deducciones racionalistas procedentes de conceptos abstractos" (Weber, 1997: 851). Según Bendix un buen modo de explicar el papel desempeñado por el líder carismático en la resolución de una disputa o conflicto de intereses en la sociedad se expresa en la frase: "ir a la raíz del asunto" (Bendix, 1962: 300), o más bien, concentrarse en los efectos y valores resultantes de una decisión en lugar de fijar la atención sobre los procedimientos formales. La dominación carismática precisamente logra la leal- 
Racionalización y poder. La cuestión de la legitimidad en Weber como referente de la acción política - Nicolás Fleet

tad de las masas toda vez que trasciende las reglas establecidas para reivindicar determinados valores culturales que sirven de plano de identificación entre ésta y aquellas.

En el plano de la administración de la economía la dominación carismática no sigue un patrón muy diferente, siendo absolutamente extraña a una organización racional, es decir en términos procedimentales, de la producción y de los intercambios que aseguren una base económica estable y continua para la permanencia de la autoridad y de su cuadro administrativo. En lugar de esto prima un comunitarismo que está orientado a la satisfacción directa de las necesidades del cuadro administrativo, sin orientación alguna hacia la acumulación. En este sentido, según Weber: "[...] al lado de la comunidad doméstica el carisma es el segundo gran portador histórico del comunismo, si por él entendemos la ausencia de 'cálculo' en el uso de los bienes y no la organización racional de la producción con vistas a cualquier ordenación ('socialismo')" (Weber, 1997: 855).

La dominación carismática aparece en los contextos de crisis de legitimidad de la dominación tradicional, donde el entusiasmo de las masas sirve como respaldo político al esfuerzo de la autoridad por ponerse en contacto de manera directa con los valores que están en el fundamento de la identidad del grupo. Más adelante trataré la idea de que la dominación carismática implica una referencia a los valores materiales de la sociedad, es decir a los fines colectivos, al revisar los aspectos fundamentales de la dominación legal-racional, frente a la cual el carisma constituye una autoridad inestable pero también un gatillo privilegiado de transformaciones sociales que apuntan a resolver las crisis de legitimidad mediante una apelación afectiva a los intereses materiales e ideales de las masas.

La dominación legal-racional, con características diferentes, es comprensible a partir de las mismas tensiones que marcan la evolución y desarrollo de los otros dos tipos de dominación legítima. Esto es, la diferenciación creciente de la sociedad y las estruc- 
turas de autoridad que de este proceso se desprenden requieren de una justificación en un plano común, que permita la existencia de niveles suficientes de solidaridad. Por cierto que este imperativo adquiere más evidencia dentro de la propia administración de la dominación: "En todas las formas de dominación es vital para el mantenimiento de la obediencia el hecho de la existencia del cuadro administrativo y de su acción continua a la realización e imposición de las ordenaciones. La existencia de esa acción es lo que se designa con la palabra 'organización'. Para ella, a su vez, es decisiva la solidaridad (ideal o real) de intereses del cuadro administrativo con el soberano. En las relaciones del cuadro administrativo con le soberano rige esta ley: que el imperante, apoyado en esa solidaridad, es más fuerte frente a los miembros individualmente considerados, pero es más débil frente a todos ellos en conjunto" (Weber, 1997: 212).

Ahora bien, como ya hemos visto, tal solidaridad corresponde a la incorporación de intereses particulares, y, de esta manera, los valores colectivos que la representan van evolucionando a partir de conflictos y pugnas entre estos intereses particulares. La dominación legal racional emerge a partir de la crisis de legitimidad de las sociedades tradicionales, donde la solidaridad sujeta a la tradición es insatisfactoria para los intereses de nuevos grupos sociales emergentes, que reconfiguran el esquema de identidad del grupo, y cuestionan sus formas de autoridad. Si se quiere poner en estos términos, la dominación legal racional es el resultado de la presión de parte de intereses particulares por ampliar el esquema de representación y participación política, lo cual determina una transformación consecutiva en los mecanismos de legitimación de la autoridad, de acuerdo a estos nuevos intereses y esta nueva identidad de una sociedad altamente diferenciada y estructurada en torno a relaciones de poder que necesitan de justificación. Al mismo tiempo, y al igual que en los otros dos tipos de dominación legítima, dentro del propio esquema de dominación legal racional podemos encontrar presiones hacia la incorporación de nuevos intereses particulares y 
Racionalización y poder. La cuestión de la legitimidad en Weber como referente de la acción política - Nicolás Fleet

nuevas justificaciones para los intereses que predominan, lo cual puede desembocar en la siguiente tensión: los valores generales que dan cuenta de la identidad del conjunto de la sociedad no siempre van a satisfacer los intereses concretos y actuales de los grupos dominados, conduciendo a un proceso de crisis que bien puede resolverse incorporando nuevos valores e intereses en el universo general de la legitimidad o bien puede derivar en un cuestionamiento del conjunto del sistema de dominación, es decir, en una transformación política de la sociedad. Pero, vamos por partes.

Para Weber son los intereses de las nacientes burguesías en la Europa moderna quienes van a ejercer presión para que la administración de los asuntos públicos adquiera un carácter centralizado, continuo, estable, y que permita excluir del horizonte de oportunidades de inversión y ganancia la incertidumbre propia de la arbitrariedad tolerada y justificada por el esquema de dominación tradicional y carismática. Según Weber, "un cierto grado de economía monetaria constituye un supuesto normal, si no para la formación, cuando menos para la prosecución inalterada de los regímenes puramente burocráticos" (Weber, 1997: 723). Este proceso va a estar acompañado y complementado por la pugna entre las autoridades locales por controlar un territorio mayor, dando origen a las semillas de lo que serán hacia el siglo XIX los Estados Nacionales. En efecto, lo que por un lado aparece como los intereses de los sectores capitalistas por controlar los ámbitos susceptibles de explotación económica en un marco de estabilidad y administración calculable, con el objeto de movilizar la fuerza de trabajo y expropiarla de los medios de producción, por el otro lado aparece como los interés de la autoridad política de centralizar el poder, expropiando a los propios príncipes patrimoniales de los medios de administración, lo que marca del origen de la burocracia profesional. En el fondo, ambos movimientos responden, en el pensamiento de Weber, a un solo impulso racionalizador, que tiende a difundir la separación entre los individuos y los medios de producción sin limitarse única- 
mente a la esfera económica, alcanzando todos los ámbitos de la organización de la sociedad, los cuales adquieren una estructura burocrática, jerarquizada y sometida a un proceso de expropiación. La dominación legal-racional, que combina en sus inicios tales intereses materiales de sectores económicos y políticos, resulta en una especialización creciente de todas las actividades y en un proceso de división del trabajo que, aún cuando arranca del avance del capitalismo moderno, Weber lo encuentra típicamente representado en la organización burocrática de la política.

Desde luego, para Weber un factor decisivo de está centralización y especialización del poder lleva consigo la necesidad de que el Estado controle para sí a la violencia como medio último y legítimo en el logro de sus objetivos, cualquiera estos sean. Sin embargo, esta concentración de los medios violentos para el ejercicio del poder en manos de la autoridad política no tiene sentido si es que no es interpretado como la contraparte de un proceso de constitución de los mercados del trabajo y de capitalización de las relaciones laborales, de acuerdo a los intereses de quienes tienen los medios de producción, donde la violencia termina siendo empujada fuera de los contratos de trabajo. En la opinión de Giddens, este cruce entre la formalmente libre contratación de mano de obra como trabajo abstracto y remunerado y el estado nacional como monopolio legítimo de la violencia física, corresponde a una de las dimensiones institucionales más decisivas de la modernidad (Giddens, 1990: 62).

El desarrollo del tipo de dominación legal-racional, en efecto, es impensable sin tal centralización del poder, monopolio de la violencia en manos de la autoridad y también de la constitución de una determinada comunidad política, en tanto base de la unidad de la cultura y marco de referencia simbólica para la acción administrativa ejercida por el aparato de dominación. Esto último es clave, ya que toda pretensión de dominación legítima, para presentarse a los ojos de los dominados como "totalidad" o, si se quiere, como "interés general", requiere anclarse en la solidaridad 
Racionalización y poder. La cuestión de la legitimidad en Weber como referente de la acción política - Nicolás Fleet

del grupo y solo tiene vigencia dentro de sus límites. En este caso particular, el tránsito entre un tipo de dominación tradicional a otro legal-racional constituye la superficie de un cambio más profundo, donde las solidaridades se transfieren desde pertenencias comunitarias hacia la formación de una identidad nacional. La nación constituye la comunidad política propia de las sociedades modernas, y de ella se extraen los niveles de solidaridad e identidad suficientes que hacen posible la legitimación de la autoridad estatal. La exigencia de identificación con la nación responde a "[...] la necesidad del proyecto político de la modernidad de contar con una comunidad para la que las decisiones de aparato burocrático [...] sean vinculantes y desde la cual emane la legitimidad de quienes están en la posición de tomar esas decisiones" (Mayol, 2002: 63). Ahora, desde luego, la nación no connota una realidad material ni una constatación objetiva, y se hace comprensible, más bien, desde la lógica de las representaciones colectivas; pero ¿Qué es exactamente lo que representa? En primer lugar la idea de nación remite a la autonomía, esto es, que se fija para sí sus propias orientaciones y normas. En este sentido, y en segundo lugar, es la nación la que decide sobre sus propios asuntos y forja su propio destino, un destino que es compartido, el futuro del colectivo. Por último, estas finalidades colectivas remiten a un destino político e histórico común que, como fuente de la legitimidad de la autoridad y de quienes la detentan, debe generar sentido de totalidad, una racionalidad de conjunto que diluye las particularidades en la representación de una comunidad horizontal y secular.

La nación como referente de sentido de la acción comunitaria constituye, de algún modo, una exigencia por la apertura del esquema de dominación. A la base de imagen de nación, al final, encontramos una presión de parte de los dominados por participar de la determinación de los fines colectivos. Este impulso democratizador determina la base normativa, incrustada en la comunidad política, de las actividades propias de la administración organizada racionalmente. El sentido de la acción comunitaria adquiere por medio de la organización burocrática mayores niveles de 
eficacia y precisión, es decir mayores capacidades instrumentales, concentradas en la autoridad, para la prosecución de las tareas definidas por la colectividad. "La burocratización es el procedimiento específico de transformar una acción comunitaria en una acción societaria racionalmente ordenada"(Weber, 1997: 742).

Para Weber, el tipo de dominación legal-racional encuentra justamente el origen de su legitimidad en la combinación y tensión entre los principios de la democracia y la autoridad. En consecuencia, la política es pensada como la acción orientada por estos dos polos bajo la forma de una "aspiración a la participación en el poder, ya sea entre Estados o, en el interior de un Estado, entre los grupos humanos que comprende [...]" (Weber, 1997: 1056). En su expresión moderna, la política se organiza de acuerdo a los principios de la administración burocrática, dando origen a los partidos políticos de masas como expresión de los intereses sociales. Asimismo, las presiones por participación o por determinar los fines colectivos movilizados en el Estado adquieren, según Weber, las características de una lucha entre partidos políticos donde, además de que cada cual persigue determinados fines objetivos, el objeto privilegiado de las disputas consiste en ejercer un control sobre la distribución de los cargos en el Estado. Digamos, en este punto, que la política moderna, entendida como conflicto de posiciones, se expresa en el Estado, el cual capta, mediante la participación de los partidos en su estructura, la pluralidad de orientaciones de la sociedad, legitimando su propio funcionamiento bajo la pretensión de totalidad, de interés colectivo que contiene el conjunto de los intereses particulares políticamente manifiestos. Para Weber "los órdenes estatuidos en una sociedad pueden nacer: a) por pacto libre o b) por otorgamiento -imposición- y sometimiento" (Weber, 1997: 40). Reafirmando los argumentos planteados, la tesis que se propone en este punto es que la dominación legal-racional encuentra su legitimidad a partir de la tensión entre la participación de los miembros de la comunidad política y el sometimiento a las prerrogativas del orden otorgadas desde la autoridad estatal. 
Racionalización y poder. La cuestión de la legitimidad en Weber como referente de la acción política - Nicolás Fleet

Weber enfatiza bastante este punto cuando describe las fuerzas sociales que están a la base de los procesos de burocratización de la administración. Como ya hemos visto, la política se transforma en una lucha por influir en el poder y de este modo por participar de las orientaciones de la sociedad. A esto se le agrega que para los intereses de la burguesía la burocracia tiene sentido como impugnación de los privilegios estamentales heredados del tipo de dominación tradicional. Así, "el 'gobierno de la ley' estuvo identificado con el control del gobierno por los representantes del pueblo y, por lo tanto, con la democracia, mientras que las decisiones administrativas y judiciales basadas en precedentes fueron identificados con el gobierno del juez y los peligros de reglas arbitrarias" (Bendix, 1962: 422-423). Para Weber la administración burocrática responde a un principio de nivelación de las condiciones sociales y económicas, un principio de igualdad formal que arranca desde las exigencias de parte de la sociedad por democratizar las estructuras de poder. "Se trata especialmente del irresistible fenómeno concomitante de la moderna democracia de masas en la oposición al gobierno democrático de las pequeñas unidades homogéneas. Ello ocurre, por lo pronto, a consecuencia de un principio que le es característico: la subordinación del ejercicio del mando a normas abstractas. Pues esto se sigue de la exigencia de una 'igualdad jurídica' en el sentido personal y real y, por tanto, de la condenación del privilegio y de la negación en principio de toda tramitación 'según los casos'. Pero proviene, asimismo, de las condiciones sociales previas que hacen posible su nacimiento. Todo gobierno no burocrático de una organización social cuantitativamente importante se basa en algún modo en el hecho de que los deberes y funciones de gobierno se vinculan a un privilegio social, material y honorífico ya existente [...]. La democracia de masas que elimina en la administración los privilegios feudales y [...] plutocráticos, debe sustituir por un trabajo profesional irremisiblemente pagado la administración tradicional ejercida al margen de toda profesión por los honoratiores" (Weber, 1997: 738). 
En la perspectiva de Bendix, "la burocracia se desarrolló con el apoyo de movimientos democráticos de demandaban igualdad ante la ley y garantías legales contra la arbitrariedad en las decisiones judiciales y administrativas" (Bendix, 1962: 437). Por lo tanto, la entrada teórica para comprender las transformaciones y transiciones de un tipo de dominación a otro debe ser encontrada en los actores sociales concretos que al interior de las sociedades históricas luchan por hacer caber sus intereses particulares al interior del ámbito de representación política. La legitimidad de la dominación, al final, nos permite dar cuenta de tal incorporación de intereses materiales e ideales y, de esta manera, comprender la base social particular de las orientaciones generales de la sociedad, ámbito simbólico que sirve de justificación del poder y de su uso en nombre de la totalidad. Del mismo modo, la lógica de las "crisis de legitimidad" refieren directamente a las transformaciones que se constatan en la base social misma, de tal suerte que cambios en la identidad del grupo, es decir, la formación de nuevos sectores sociales y su constitución en actores con reivindicaciones específicas, terminan alterando las formas de autoridad de la sociedad y sus justificaciones ad-hoc. Ahora bien, todos estos procesos no deben entenderse nunca de un modo mecánico, como si existiera un flujo transparente entre el ámbito de formación de actores sociales y el ámbito de la autoridad legítima, sino que la lógica de las transformaciones de los tipos de dominación, y en especial de la racionalización, que no es otra cosa que el curso que toman tales procesos en las sociedades modernas, tienen efectos que van más allá del control de las intenciones de las fuerzas sociales que los empujan. En el caso particular de la dominación legal-racional, la ganancia en términos de igualdad formal tuvo resultados equívocos desde la perspectiva de los valores democráticos.

\section{Racionalización de la vida económica y política}

Weber se propone usar el concepto de dominación (Herrschaft) en un sentido estrecho, excluyendo de su alcance todas esas situa- 
Racionalización y poder. La cuestión de la legitimidad en Weber como referente de la acción política - Nicolás Fleet

ciones en las cuales el poder es derivado de constelaciones de intereses. Esto nos lleva a la distinción entre dominación legítima, correspondiente a la autoridad establecida, que ejerce el derecho de ordenar y exige el deber obedecer, y dominación no-legítima, correspondiente a las constelaciones de intereses que rigen el movimiento de los mercados formalmente libres. El análisis de los procesos de racionalización de la sociedades modernas hecho por Weber se centra en estos dos ámbitos, de manera de develar los intereses sociales que han estado detrás de la institucionalización de la acción racional con arreglo a fines en las esferas organizacionales del Estado y la empresa. Sin embargo, aún cuando compartan las mismas raíces históricas y sean consecuencia de los mismos procesos, aún cuando se hayan asociado y reforzado mutuamente para contribuir a la formación de las instituciones sociales y políticas de la modernidad, se diferencian en el modo de resolver la contradicción entre los intereses particulares y los imperativos de solidaridad e integración social. En otras palabras, en el espacio de la política, como hemos venido insistiendo, los mandatos concretos, que por cierto también responden a intereses concretos y particulares, deben justificarse como legítimos, es decir, exhibirse como intereses generales para el conjunto de la sociedad. En cambio, cuando nos referimos a la esfera del mercado, el predominio de unos intereses sobre otros, y las consecutivas estructuras de desigualdad que de esta contingencia se desprenden, no requieren justificarse más allá de una igualdad y libertad formales en el ámbito del contrato.

En efecto, tal como lo señala Peter M. Blau, la manera de asegurar la legitimidad de la autoridad suele estar en que el superior persiga satisfacer los intereses del grupo. En cambio, la vida económica persigue la optimización de sus procesos con el objeto de incrementar el beneficio individual, pero esto lo hace con abstracción de toda orientación hacia el abastecimiento o la satisfacción de las necesidades del grupo. Las desigualdades entre autoridad y subordinados se expresan en la política como un poder ejecutado en nombre del bien colectivo. En cambio, las desigualdades 
de oportunidades de mercado, o desigualdades de clase en la terminología weberiana, se expresan como un poder que sirve directamente a intereses particulares. Obviamente, el tema del predominio de lo particular cruza todo el pensamiento de Weber, empero, en el caso particular de la dominación legítima es ineludible la promesa de la realización del interés general.

Weber fue un testigo alarmado de cómo la exclusión y dominación en el mercado comenzaba a adquirir ribetes políticos y comenzaba a expresarse en la forma de voluntades partidistas. Para él resulta evidente que la racionalización de la vida económica solo se cristaliza como mayores capacidades instrumentales para la prosecución eficaz de los intereses dominantes, sin que el tema de la distribución de los resultados del proceso económico se tradujera en alguna política salarial o de nivelación de las condiciones de vida, favoreciendo, más bien, los procesos de acumulación privados. El juicio de Weber, en este sentido, es que se produce una separación cabal entre la racionalidad formal de la producción, orientada a la optimización de los medios para incrementar las ganancias, y su racionalidad material, orientada a la satisfacción de necesidades. La economía propiamente liberal solo es racional en términos formales, mientras que en el ámbito de lo material, digamos en las orientaciones hacia el 'valor de uso', permanece sin ser tocada por la lógica del cálculo, de modo que la satisfacción de las necesidades colectivas es obtenida como resultado del azar. Según Weber, "esta irracionalidad fundamental e insoluble de la economía es la fuente de toda 'problemática social' y especialmente de todo socialismo" (Weber, 1997: 85).

La preocupación de Weber en este punto es la misma que tiene Durkheim cuando sostiene que las formas democráticas de formación de la voluntad política que legitiman el esquema de dominación burocrática y los imperativos éticos que toman cuerpo en la formulación positiva del derecho son demasiado débiles para poner coto a los efectos desintegradores de la división anómica del trabajo, es decir, organizada en torno a contratos 
Racionalización y poder. La cuestión de la legitimidad en Weber como referente de la acción política - Nicolás Fleet

individuales que no consideran el interés de la totalidad. Frente a este estado de las cosas, desde la propia sociedad, se ejercen presiones irresistibles a la incorporación de valores particulares o 'leyes sociales' en el marco abstracto del derecho y como finalidades para ser ejecutadas por la organización burocrática. Por ejemplo, en la visión de las teorías socialistas, la legitimidad del orden social sobre las bases del 'contrato' se erosiona a partir de consideraciones materiales referidas bien al 'derecho a trabajar' o bien apelando a la reivindicación de un 'salario vital'. Sea como sea, Weber en su época ve como el Estado debe intervenir en la vida económica para asegurar condiciones de justicia sustancial mínimas de manera de evitar que la legitimidad formal del orden político sea negada por las condiciones de dominación no legítima del mercado. Esta situación emergente acarrea, en la perspectiva de Weber, el peligro de burocratizar excesivamente no solo el propio funcionamiento de la política sino también de la economía, de acuerdo a los intereses de la autoridad política, orientados a la conservación del orden social por medio de un tipo de legitimación que no se conforma solo con el ejercicio de la legalidad sino que hace concesiones a los intereses particulares que, insatisfechos con sus oportunidades de vida en el mercado, demandan mayores niveles de bienestar al Estado. En definitiva el peligro al cual Weber se refiere consiste en que las demandas de los desposeídos sirvan para fortalecer el influjo de la burocracia sobre el conjunto de la vida social, de manera que por parte de la autoridad política la satisfacción de tales necesidades materiales vigentes en la sociedad sirva de excusa para incrementar su poder. En sus propias palabras: "El motivo por el cual insisto en toda ocasión tan especial y señaladamente contra la interferencia de Lo-que-debe-ser con Lo-existente, no es porque subestime la cuestión del 'debe', sino que exactamente al contrario: porque no puedo tolerar que se convierta aquí en una 'cuestión de productividad' técnico- económica y en objeto de discusión de una especialidad como es la economía nacional lo que en realidad son problemas de trascendencia mundial, de gran envergadura de ideas, 
en cierto sentido, problemas supremos que pueden conmover el alma del hombre" (Marcuse, 1970: 118).

La posición de Weber con respecto a este problema era directamente que la emancipación de la clase obrera no debía ser el resultado de la política social de un Estado benefactor y previsor, sino una conquista realizada por la fuerza e iniciativa de la propia clase obrera. "El papel del Estado en el plano social debe limitarse a asegurar a los antagonismos sociales [...] la igualdad de oportunidades en el marco de un sistema jurídico que fija las reglas del juego" (Mommsen, 1971:110). Sin embargo, y contraviniendo las aprehensiones de Weber, las consecuencias que tuvieron tales luchas políticas de los sectores postergados influyeron en el fortalecimiento del poder estatal y de los medios disponibles para la autoridad para proveerse de legitimidad. En este sentido, la legitimidad de la dominación legal-racional transitó efectivamente desde un derecho puramente positivo, es decir, que no guarda ninguna vinculación necesaria con la moral, hacia una justicia de índole material que considera determinados fines sociales y objetivos políticos que son protegidos y promovidos por el Estado por sobre los intereses individuales predominantes en el mercado. En este proceso de transformación de las bases de la legitimación de la dominación legal-racional contribuyen, en primer lugar, las reivindicaciones antiformales por justicia sustantiva que fueron promovidas por las demandas de 'leyes sociales' de parte de los actores no privilegiados de la sociedad. Se trata de una impugnación a las asimetrías que se constatan en la distribución de la riqueza social, y que, en el marco del Estado, resuelve las tensión entre justicia formal y justicia sustancial mediante la diferenciación de los derechos formales, que típicamente sirven de fuente de legitimación de la dominación legal-racional, y los derechos emanados de la acción de los grupos sociales. En segundo lugar, la autoridad política jugó un papel fundamental en la elaboración de un derecho que respondiera las nuevas condiciones materiales y prácticas, quienes estuvieron dispuestos, en este sentido, "a sacrificar la precisión jurídica puramente formal" 
Racionalización y poder. La cuestión de la legitimidad en Weber como referente de la acción política - Nicolás Fleet

(Freund, 1986: 234)1․ En tercer lugar, y de un modo más marginal, contribuyen a este proceso los intereses de la profesión legal, en la medida en que la importancia de la ley casuística y la consideración de casos especiales tienden a elevar el sentimiento de importancia propia y a incrementar su sentido del poder: "la idea de un derecho sin lagunas ha sido, de principio, violentamente combatida y la concepción del juez moderno como un autómata a quien se entregan las actas y las costas con el fin de que formule un juicio según razones mecánicas deducidas de los párrafos legales ha sido también enérgicamente rechazada, tal vez porque cierta aproximación a este tipo sería la consecuencia de la burocratización del derecho" (Weber, 1997: 734-735).

Lógica jurídica formal

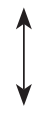

Libertades individuales
Exigencias materiales

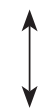

Imperativos colectivos

El modo de legitimación de la autoridad política en el marco de la dominación legal-racional es el campo mismo de las luchas por el poder, donde los resultados de estos conflictos de intereses expresados en la forma de partidos se manifiestan de forma decisiva en la creación de nuevas reglas y leyes vinculantes, que determinan la dirección de la totalidad social incluyendo a la propia autoridad. La legitimación como disputa por el poder corresponde al juego político de influir y competir por votos dentro de las organizaciones partidistas, de manera de participar en el proceso legislativo de promulgar leyes y supervisar su ejecución. Ahora bien, esta imagen de la política como enfrentamiento entre adversarios, y el resultado de este enfrentamiento como las condiciones de legitimidad de la autoridad, plantean tensiones con el universo formal del derecho que es el corazón mismo de orden legal-racional. En efecto, Weber ve en la actividad política una voluntad de imponer al conjunto, finalmente con el respaldo del

1 Freund, Julien: “Sociología de Max Weber", página 234; Península; Barcelona; 1986. 
aparato coactivo del Estado, intereses particulares que provienen de la sociedad y que eventualmente se pueden contraponer a los imperativos éticos del derecho positivo que tiene por finalidad solamente la preservación del orden en la sociedad. La política va, entonces, de la mano con la "culpa ética" de realizar determinados valores particulares en contraposición a los imperativos del orden. Por ejemplo, poner el poder al servicio de una huelga con el fin de obtener ventajas materiales (mejor salario y otras condiciones de trabajo) no tiene nada de político si esta manifestación no busca la dominación del grupo territorial en su conjunto, es decir, si respeta la autoridad instituida y los reglamentos. Si se me permite la siguiente analogía, desde luego guardando las proporciones, con la obra de Fedor Dostoievwski "Crimen y Castigo": "todos los legisladores y guías de la humanidad, empezando por los más antiguos y terminando por Licurgo, Solón, Mahoma, Napoleón, etcétera; todos, hasta los más recientes, han sido criminales, ya que al promulgar nuevas leyes violaban las antiguas, que habían sido observadas fielmente por la sociedad y transmitidas de generación en generación, y también porque esos hombres no retrocedieron ante los derramamientos de sangre (sangre inocente y a veces heroicamente derramada para defender las antiguas leyes), por poca que fuese la utilidad que obtuvieran de ello" (Dostoiewski, 1986: 262).

“La 'igualdad jurídica' y la exigencia de garantías jurídicas contra la arbitrariedad requiere una objetividad racional formal por parte del régimen de gobierno, en oposición a capricho personal libre derivado de la gracia propia de la antigua dominación patrimonial. Sin embargo, cuando en alguna cuestión particular el ethos domina a las masas -y queriendo prescindir de otros instintos-, los postulados de la 'legalidad material' encaminados al caso concreto y a la persona concreta chocan inevitablemente con el formalismo y con la fría 'objetividad' normativa del régimen de gobierno burocrático, de suerte que entonces debe rechazarse emotivamente 
Racionalización y poder. La cuestión de la legitimidad en Weber como referente de la acción política - Nicolás Fleet

por esta razón lo que había sido racionalmente exigido. En particular deja insatisfechos a las masas desposeídas la 'igualdad jurídica' formal y la justicia y el gobierno 'calculables', tal como lo exigen los intereses burgueses. Para tales masas, el derecho y el gobierno tienen que estar al servicio de la nivelación de las probabilidades de vida económicas y sociales enfrente de los poseedores, y solamente pueden desempeñar esta función cuando asumen un carácter no formal, es decir, un carácter sustancialmente ético [...]. No solamente se opone al curso racional de justicia y del gobierno [...] toda clase de 'justicia popular', sino también toda clase de influencias ejercidas sobre el gobierno por la llamada 'opinión pública', es decir, cuando existe una democracia de masas, por una acción brotada de 'sentimientos irracionales' preparados y dirigidos normalmente por los jefes de partido y de prensa" (Weber, 1997: 735-736).

La insistencia de Weber cómo el conflicto político puede llevar, y en efecto lleva a este tipo de situaciones, la plantea en su temor, en primer lugar, a que los intereses de las masas desposeídas sean movilizados en favor de la autoridad política personal, donde, tal como lo veía en la Alemania de su época, la debilidad en la organización política de los intereses sociales sea aprovechada de un modo oportunista por llamamientos al cesarismo. En segundo lugar, su temor se plantea en la medida en que las demandas por ejercer un control sobre la vida económica en términos de una racionalización material orientada al abastecimiento impulse una expansión sin precedentes del régimen burocrático, donde la dominación del saber experto del funcionario se realice sin contrapesos de parte de las exigencias de libertad individual. Muy citados son, en este controvertido punto, las críticas a las presiones sociales por la socialización de la producción y el control político sobre la división del trabajo que, aludiendo a las ideologías socialistas, en lugar de conducir a una 'dictadura del proletariado' terminarían por instalar la 'dictadura del funcionarado'. 
En el marco de estas tendencias, que anuncian el ascenso del capitalismo tardío, el pensamiento propiamente político de Weber se concentró en buscar alternativas que evitaran los riesgos planteados arriba. En primer lugar, en el texto "La política como vocación", Weber emplaza a los sectores sociales agrupados en torno a intereses políticos para que se movilicen hacia el Estado en un tipo de acción que combine tanto las orientaciones de la acción racional con arreglo a fines como los valores racionales que justifican frente al conjunto los intereses particulares de acuerdo a criterios generalizables. Por un lado, la acción política debe evitar la búsqueda del poder por el poder, que lleva inevitablemente, a un estancamiento del conjunto de la sociedad en la medida en que el propio Estado queda desprovisto de finalidades y solo es objeto de disputas mezquinas por prebendas, por determinadas concesiones legales, convirtiéndose, de este modo, en el espacio del aprovechamiento oportunista de situaciones para incrementar el poder de la burocracia. Weber veía en la burguesía de su época una actitud de este tipo, quienes se servían de la política para encontrar la satisfacción de intereses inmediatos sin instalar liderazgos potentes. Este aprovechamiento individualista de la política recibe en Weber una explicación en la racionalización de la conducta de los sectores burgueses por efecto de la ética religiosa calvinista. Asimismo, el privatismo civil que se desprende de tal racionalización de la personalidad eventualmente puede derivar en una abdicación del ejercicio decisivo del poder a cambio del bienestar, lo que influye en el fortalecimiento de los procesos de centralización del poder. Según lo anterior, en la perspectiva de Giddens, un importante tema subyacente en "La ética protestante" consiste en identificar las fuentes históricas de dicha 'conciencia burguesa'. Por el otro, la política debe evitar la falta de responsabilidad, de hacerse cargo de las consecuencias de las invocaciones a determinadas demandas particulares que, cuando no están acompañadas de una organización política resuelta, son aprovechadas por la autoridad para movilizarlas de acuerdo a su propio beneficio. Weber, en la descripción de esta acción política 
Racionalización y poder. La cuestión de la legitimidad en Weber como referente de la acción política - Nicolás Fleet

idealista, se refería a los socialdemócratas alemanes, porque éstos pedían al curso objetivo de la historia la seguridad de su victoria inminente, en vez de tratar de obtenerla por medio de una organización política responsable.

La acción política para la perspectiva de Weber debe considerar tanto sus medios, fines y consecuencias. De este modo, la combinación de una ética de la convicción, orientada a los fines, y una ética de la responsabilidad, orientada a los medios y consecuencias, resultan en un liderazgo político sólido, que resuelve éticamente el problema de "la violencia legítima en manos de las asociaciones humanas" (Weber, 1981: 171) y la cuestión de los efectos del poder. Estos mismos argumentos sirven a Weber para su propuesta acerca de la organización de los procedimientos de representación democrática y el papel desempeñado por los líderes políticos. En un primer acercamiento, Weber distingue entre los políticos profesionales, los burócratas, y el político por vocación, el líder. La diferencia entre ambos radica en los niveles de responsabilidad, ya que mientras la burocracia solo es responsable con respecto a la ejecución de los medios, el político demuestra su capacidad de acción independiente, de la cual él es el único responsable. De algún modo, los fines y la decisión sobre la pluralidad de éstos, es un asunto que corresponde al liderazgo político. Weber, de esta manera, reclama la existencia de un poder verdaderamente fuerte como el único que tiene la capacidad de realizar una gran obra creadora en la sociedad, en tanto que un gobierno puramente burocrático nunca podrá superar los límites del orden establecido ni franquear la lógica estructurada del cambio planificado. Una vez más, el pensamiento de Weber tiende a identificarse con la fuerza innovadora que vimos en el caso de la dominación carismática. En efecto, a la cabeza de toda la organización racional del aparato burocrático se pone un elemento no racional, un liderazgo político que ejecuta las decisiones atendiendo a los intereses y valores vigentes en la sociedad, $y$, en la mayoría de los casos, a través de la mediación de los líderes de los partidos. 
Naturalmente, Weber no se entusiasma, en este sentido, con el modelo planteado por los gobiernos bonapartistas, y considera la necesidad de la democracia plebiscitaria como el equilibrio para el ejercicio de la autoridad legítima. De este modo, las tendencias a la concentración del poder en las manos del líder o en una burocracia incontrolada que rige de acuerdo al saber experto, tienen un contrapeso en la democracia parlamentaria que asegura tanto un flujo transparente de información desde las actividades ejecutadas por el aparato burocrático hacia los representantes populares, como un planteamiento abierto a la opinión pública de las responsabilidades derivadas de las decisiones políticas del líder. En definitiva el esquema de la democracia plebiscitaria contiene las tendencias incrustadas en la dominación legal-racional a la abolición de la libertad individual, tema que, como hemos visto, constituye la preocupación fundamental de la sociología weberiana. Se aplica la frase: "una libertad tan grande como sea posible por medio de una dominación tan grande como sea posible".

Limita el poder del líder, mediado por el orden del derecho.

Democracia Pacto de los interesados / parlamento

Dominación legal

Plebiscitaria

Legítima del Líder

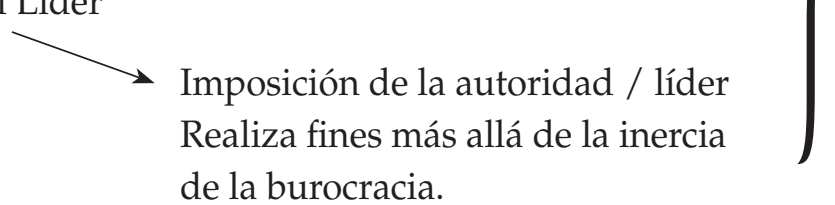

\section{Referencias}

Blau, Peter M. (1970). "Critical remarks on Weber's theory of authority" en Wrong, Denis: Max Weber; Prentice Hall; Englewood Cliffs, N.J.

Bendix, Reinhard (1962). Max Weber: an intellectual portrait; Anchor Books; New York. 
Racionalización y poder. La cuestión de la legitimidad en Weber como referente de la acción política - Nicolás Fleet

Dostoiewski, Hedor (1986). Crimen y castigo; Editorial Juventud; Barcelona. Freund, Julián (1986). Sociología de Max Weber; Península; Barcelona.

Giddens, Anthony (1976). Política y Sociología en Max Weber; Alianza Editorial; Madrid.

(1990). The consequences of modernity; Stanford University Press; Stanford, California.

Marcuse, Herbert (1970). "Industrialización y capitalismo en la obra de Max Weber" en Ética de la revolución; Editorial Taurus; Madrid.

Mayol, Alberto (2002). En busca del paradigma político de la modernidad. Aproximación a las teorías políticas de Max Weber y Jürgen Habermas. Tesis para optar el título profesional de sociólogo. Universidad de Chile; Santiago de Chile. Mommsen, Wolfgang (1971). "La sociología política de Max Weber y su filosofía de la historia universal" en Sazbón, José: Presencia de Max Weber; Editorial Nueva Visión, Buenos Aires.

Parsons, Talcote (1949). The Structure of Social Action; The Free Press; Glencoe, Illinois.

Serrano Gómez, Enrique (1994). Legitimación y racionalización. Weber y Habermas: la dimensión normativa de un orden secularizado; Editorial Anthropos; Barcelona.

Turner, Stephen P. y Factor, Regis A. (1994). Max Weber: The lawyer as social thinker; Routledge; London.

Weber, Max (1981). El político y el científico; Alianza Editorial; Madrid.

(1997). Economía y sociedad; Fondo de Cultura Económica; Santafé de Bogotá.

(2001). Ensayos sobre sociología de la religión, Tomo I; Editorial Taurus; España. 